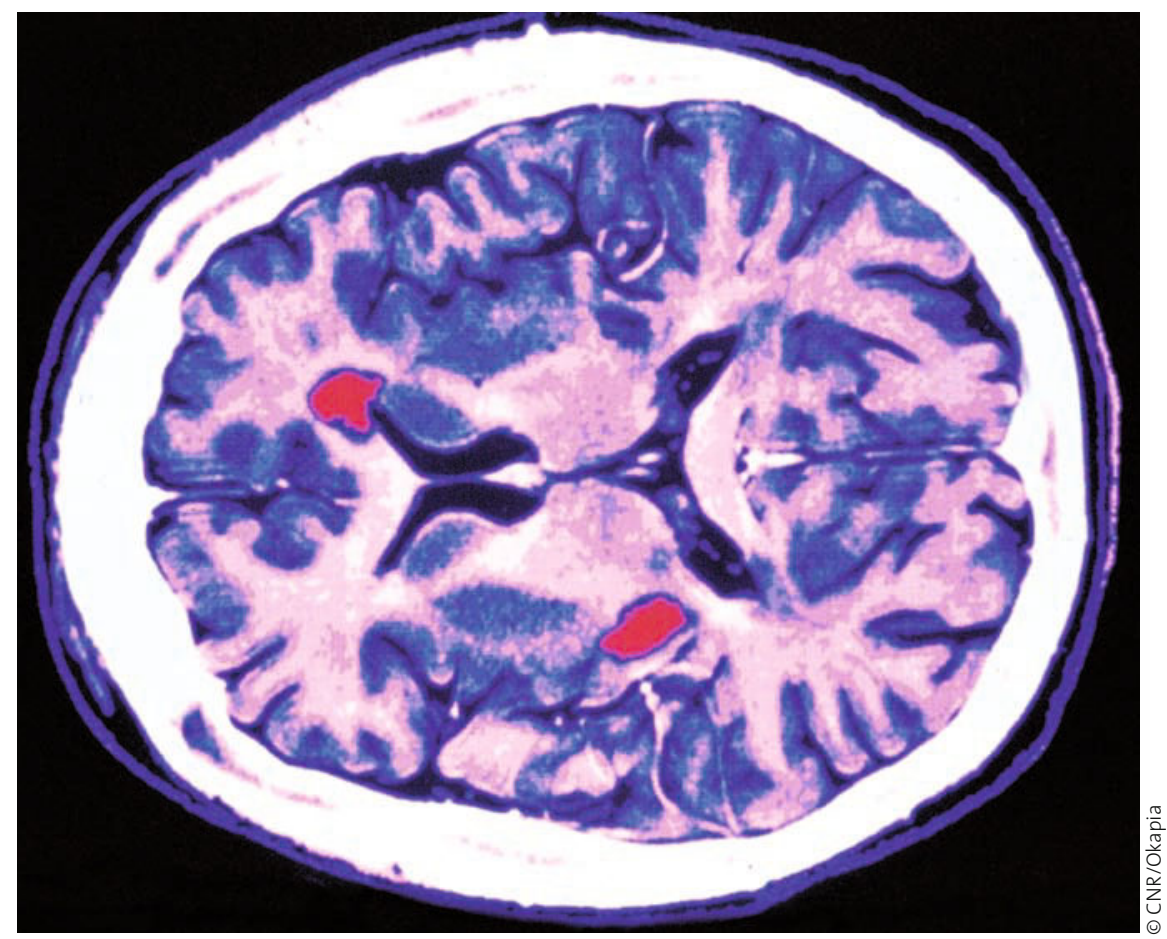

Zerebrale Läsionen im Frühstadium einer MS.

\title{
Aktivität der Multiplen Sklerose ändert sich mit der Jahreszeit
}

Der Krankheitsverlauf der Multiplen Sklerose (MS) ist mit den Jahreszeiten verbunden. Hohe Temperaturen und intensiver Sonnenschein im Sommer verstärken die Symptome. Ein Krankheitsschub ist im Sommer häufiger als im Winter.

- Wissenschaftler der University in Boston bestimmten in einer Beobachtungsstudie mit der MRI neue, sog. T2-gewichtete Hirnläsionen - empfindliche Marker für eine subklinische MS-Aktivität. Bei 44 unbehandelten MS-Patienten wurde die Krankheitsaktivität anhand des Erscheinens der neuen T2-Läsionen in 939 MRT-Aufnahmen eingeschätzt. Sie wurde mit den zu gleichen Zeit registrierten Klimadaten der Jahreszeit und Region, insbesondere der Sonnenstrahlung, verglichen.

Die wichtigsten Ergebnisse waren: Von März bis August war die MS-Aktivität zwei- bis 2-3- Mal höher als im restlichen Jahr. Sie korrelierte stark mit den regionalen Klimadaten, insbesondere mit der Sonnenstrahlung. Bei der progressiven MS waren die Aktivitätszunahmen kleiner und zwei Monate früher.

\section{Kommentar}

Die Studie dokumentiert ein saisonales Muster der subklinischen MS-Aktivität. Diese Erkenntnis ist bedeutsam und sowohl bei der Planung zukünftiger Studien als auch bei der Therapie zu beachten. Denn scheinbar positive und auch negative Studienergebnisse könnten allein Folge des unterschiedlichen Zeitpunkts der Studie sein.

K. MALBERG =

\section{- D. S. Meier et al.}

(Center for Neurological Imaging, Brigham \& Women's Hospital, 221 Longwood Avenue, RF396, Boston, MA 02115, USA ;E-Mail: meier@bwh.harvard.edu) Seasonal prevalence of MS disease activity. Neurology 75 (2010) 799-806 